\title{
De Nederlandse Kankerregistratie; een schat aan informatie
}

\author{
Katja K. H. Aben ${ }^{1}$ Rob Verhoeven ${ }^{1}$ Antoinette de Vries ${ }^{1}$
}

Published online: 15 November 2016

(C) The Author(s) 2016. This article is available at SpringerLink with Open Access.

Samenvatting Er bestaat een toenemende belangstelling voor het inzichtelijk maken van (variatie in) kwaliteit van oncologische zorg. Naast de bestaande, veelal monodisciplinaire kwaliteitsregistraties, kan de Nederlandse Kankerregistratie (NKR) dienen als bron van gegevens ter evaluatie van bepaalde aspecten van kwaliteit van uro-oncologische zorg. Indien de beschikbare gegevens ontoereikend zijn, is uitbreiding van de standaardregistratie in de NKR mogelijk. Voor prostaatkanker is in 2015 door onderzoekers van IKNL (Integraal Kankercentrum Nederland), samen met de betrokken wetenschappelijke verenigingen, een uitgebreide kwaliteitsregistratie gestart, een vergelijkbaar initiatief voor blaaskanker volgt. Uitgangspunten bij deze registraties zijn: multidisciplinair, onafhankelijk, goede kwaliteit en uniformiteit, gecombineerd met een zo laag mogelijke registratielast voor medisch specialisten. Op basis van deze registraties wordt variatie in zorg in kaart gebracht, en worden factoren die ten grondslag liggen aan die variatie geïdentificeerd, waardoor de zorg verbeterd kan worden.

Trefwoorden kwaliteit van zorg • prostaatkanker . blaaskanker · Nederlandse Kankerregistratie (NKR)

\section{The Netherlands Cancer Registry; a wealth of information}

Abstract In the past years there has been an increased focus on (variation in) quality of oncological health care. The

dr. Katja K. H. Aben

k.aben@iknl.nl

1 Afdeling Onderzoek, Integraal Kankercentrum Nederland (IKNL), Utrecht, Nederland
Netherlands Cancer Registry (NCR) can be used to evaluate relevant aspects of quality of uro-oncological care. As detailed data are needed to evaluate quality of care, often additional data have to be collected. In 2015, researchers of IKNL have, in close collaboration with all involved medical disciplines, started an extensive data collection concerning prostate cancer care within the NCR. Similar actions will be taken for bladder cancer. Key considerations are: multidisciplinary, independent, high quality and uniformity together with a minimal registration burden for the involved clinicians. Based on the extensive clinical dataset variation concerning relevant aspects of prostate and bladder cancer care will be evaluated, underlying factors will be identified which ultimately leads to improved care.

Keywords Quality of care - Prostate cancer - Bladder cancer $\cdot$ Netherlands Cancer Registry

\section{Introductie}

De afgelopen jaren geniet evaluatie van kwaliteit van oncologische zorg steeds grotere belangstelling. Zowel zorgprofessionals, als patiëntenverenigingen, overheid, KWF Kankerbestrijding, zorgverzekeraars en andere partijen zijn betrokken bij het proces dat meer inzicht moet geven in de variatie die binnen de kwaliteit van zorg bestaat, teneinde een verbetering in zorg te bewerkstelligen, die uiteindelijk moet leiden tot verbeterde overleving en kwaliteit van leven van de patiënt.

Om meer inzicht te krijgen in de kwaliteit van zorg bij urologische tumoren is de Nederlandse Vereniging voor Urologie (NVU) in 2008 gestart met een landelijke kwaliteitsregistratie van prostatectomieën, later gevolgd door een registratie van cystectomieën en nefrectomieën. Via 


\section{Hier staat een advertentie.}

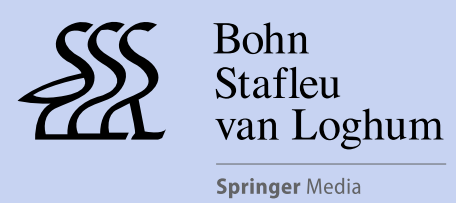

Houten 2017 


\section{Hier staat een advertentie.}

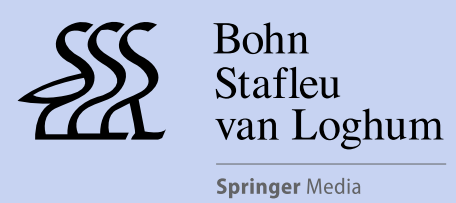

Houten 2017 
deze registraties is het voor de uroloog mogelijk om de chirurgische resultaten in te zien en deze te vergelijken met landelijke gemiddelden. Naast deze kwaliteitsregistraties zijn er andere initiatieven genomen om variatie in zorg voor patiënten met urologische tumoren in kaart te brengen, zoals het CAPRI-project (CAstration-resistent Prostate Cancer Registry). Binnen dit project worden uitkomsten van CRPC-behandeling in de dagelijkse praktijk geëvalueerd door in 20 Nederlandse ziekenhuizen informatie te verzamelen van patiënten met castratieresistent prostaatcarcinoom. Daarnaast zijn er lokale kwaliteitsregistraties in individuele en samenwerkende ziekenhuizen (zoals binnen het Santeon samenwerkingsverband).

Variatie in de kwaliteit van de oncologische zorg is ook te onderzoeken met gegevens uit de Nederlandse Kankerregistratie (NKR).

In dit artikel worden voorbeelden beschreven van de manier waarop de data uit de NKR gebruikt zijn ter evaluatie van bepaalde aspecten van de kwaliteit van zorg rond patiënten met urologische tumoren. Tevens bespreken we enkele uro-oncologische registraties in de NKR die momenteel lopen of binnenkort zullen starten.

\section{Nederlandse Kankerregistratie}

Sinds 1989 bestaat in Nederland een landelijk dekkende kankerregistratie, de Nederlandse Kankerregistratie (NKR). Integraal Kankercentrum Nederland (IKNL) beheert deze databank. De NKR is de enige oncologische ziekteregistratie in Nederland met gegevens van alle kankerpatiënten. Het Ministerie van Volksgezondheid, Welzijn en Sport financiert de basisregistratie van medische en administratieve gegevens met betrekking tot de ziekte en behandeling van patiënten in de NKR. Aanvullende (projectspecifieke) registraties zijn mogelijk, indien deze bekostigd worden door de opdrachtgever. Gegevens uit de NKR worden voor diverse doeleinden gebruikt. Allereerst worden de aard en omvang van kanker inzichtelijk gemaakt door jaarlijks incidentie-, sterfte-, prevalentie- en overlevingscijfers te publiceren (www.cijfersoverkanker.nl). Deze cijfers worden voor internationale incidentie- en overlevingsregistraties gebruikt om bijvoorbeeld vergelijkingen tussen verschillende landen te kunnen maken. Daarnaast worden data uit de NKR gebruikt ter ondersteuning van epidemiologisch en/of klinisch onderzoek, richtlijnontwikkeling en evaluatie van verschillende bevolkingsonderzoeken. Alle gegevens die zijn vastgelegd in de NKR, worden verzameld door speciaal hiervoor opgeleide datamanagers. Na signalering van nieuwe gevallen van kanker door diverse datasystemen - het Pathologisch Anatomisch Landelijk Geautomatiseerd Archief (PALGA), de Landelijke Medische Registratie (LMR)/Dutch Hospital Data (DHD) en de Diagnose
Behandel Combinatie (DBC)/'DBC's op weg naar transparantie' (DOT) - wordt door deze datamanagers, op basis van het medisch dossier in het desbetreffende ziekenhuis, een complete registratie uitgevoerd van belangrijke patiënten tumorkarakteristieken, stadiëring en primaire behandeling.

De huidige gegevensset van de urologische tumoren in de NKR bevat op dit moment algemene informatie over locatie van de tumor, histologisch type, ziektestadium (TNMstadiëring), primaire behandeling en een aantal tumorspecifieke items. Voor prostaatkanker wordt bijvoorbeeld naast TNM-stadiëring, de PSA-waarde ten tijde van de diagnose en de Gleasonscore van het biopt en de prostatectomie vastgelegd, als parameters die van belang zijn voor het indelen van patiënten in prognostische risicogroepen.

\section{De Nederlandse Kankerregistratie vernieuwt}

IKNL onderhoudt intensief contact met medisch specialisten en onderzoekers en krijgt regelmatig input over de inhoud van de gegevensset.

De afgelopen periode heeft IKNL een serie inhoudelijke en technische verbeteringen in gang gezet waardoor een vernieuwde kankerregistratie ontstaat. Dit betekent dat het registratiesysteem, waarin de gegevens worden vastgelegd, een toekomstbestendige patiënt-volgregistratie is, waarin het mogelijk is om van diagnose tot overlijden alle klinisch relevante aspecten van een patiënt/tumor vast te leggen.

Het uitgangspunt is dat voor alle vormen van kanker de eerder genoemde algemene set van gegevens op uniforme wijze wordt vastgelegd, en dat deze algemene set wordt aangevuld met een tumorspecifieke set van gegevens. Op dit moment wordt de inhoud van deze sets met de betrokken medische disciplines doorgelicht en aangepast en/of aangevuld (binnen de gegeven financiële mogelijkheden).

Een goede, betrouwbare, uniforme en valide registratie is noodzakelijk om vraagstukken in het kader van evaluatie van kwaliteit van zorg te kunnen beantwoorden. Om de kwaliteit van de gegevens verder te optimaliseren, biedt IKNL de specialist, op termijn, de mogelijkheid om zelf de registratiegegevens in te zien en deze te valideren of een voorstel voor wijziging aan te brengen. Daarnaast zal de specialist digitaal inzage krijgen in oncologische cijfers van het eigen ziekenhuis en de vakgroep die geregistreerd zijn in de NKR, en zal het mogelijk zijn om deze cijfers te vergelijken met verschillende benchmarks, zoals een regionaal gemiddelde of een gemiddelde van soortgelijke ziekenhuizen. 
Figuur 1 Behandeling van patiënten met cTla cN0 cM0-nierkanker die zijn gediagnosticeerd in de jaren 2012-2014, naar ziekenhuis waarin de diagnose werd gesteld. (Data van een aantal willekeurige Nederlandse ziekenhuizen, teneinde de anonimiteit te waarborgen.)

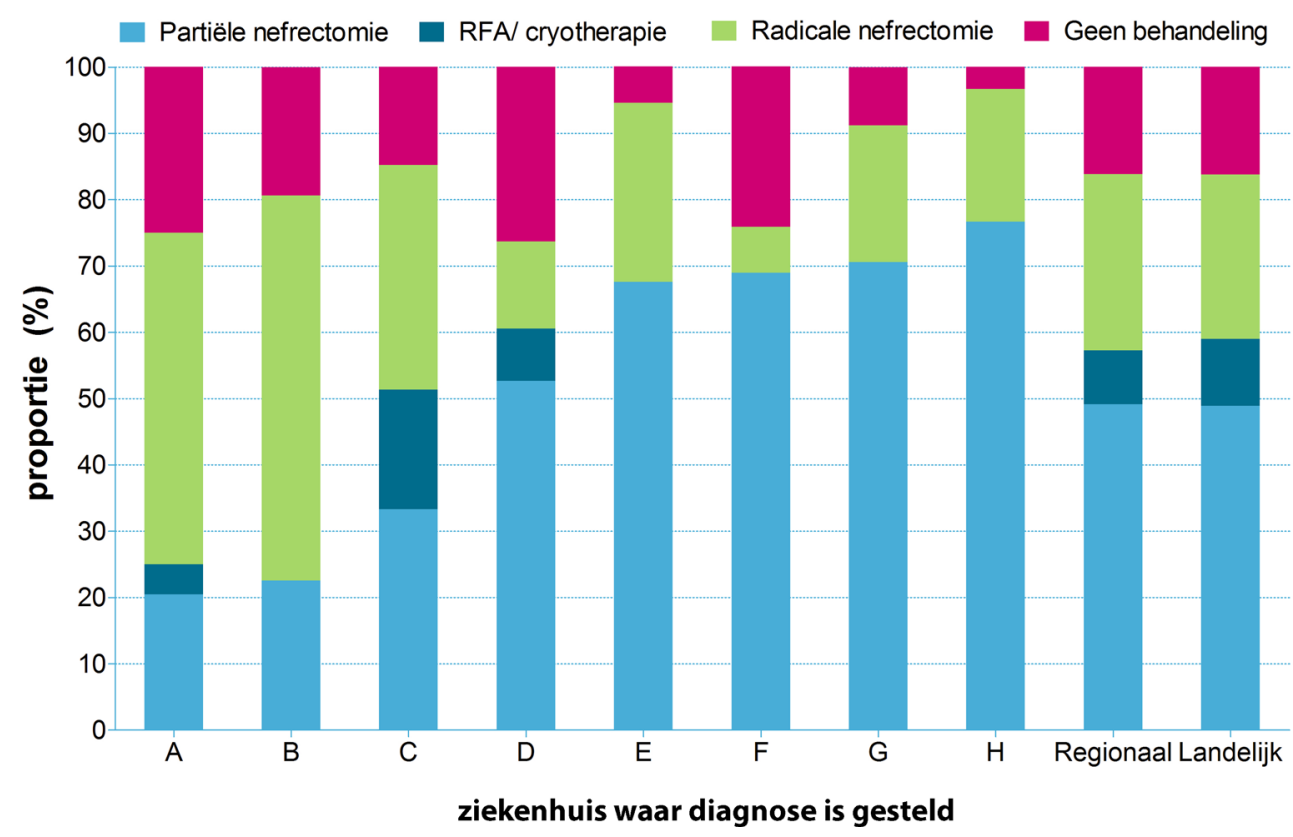

70-74 jaar en ruim $90 \%$ van patiënten jonger dan 70 jaar. Daarnaast bestaat tussen ziekenhuizen grote variatie in de proportie patiënten van 75 jaar en ouder dat een cystectomie ondergaat; dit suggereert dat het beleid tussen de verschillende ziekenhuizen verschilt. Deze variatie weerspiegelt waarschijnlijk de heterogeniteit en de complexiteit van de oudere patiëntenpopulatie. Uit ditzelfde rapport komt naar voren dat patiënten van 80 jaar en ouder met T2-prostaatkanker minder vaak een curatieve behandeling ondergaan (16\%) versus patiënten jonger dan 70 jaar (85\%); bijna een derde van eerstgenoemde groep ondergaat een hormonale behandeling (niet in combinatie met radiotherapie).

In de huidige Nederlandse richtlijn, evenals in de EAUrichtlijn, wordt aanbevolen om patiënten met een spierinvasief blaascarcinoom binnen drie maanden te opereren. In 2015 verscheen een artikel van Bruins et al. [4] op basis van data uit de NKR, waaruit bleek dat het grootste deel van de patiënten volgens deze aanbeveling werd behandeld. Het op een later moment uitvoeren van een cystectomie bleek niet geassocieerd te zijn met een hoger ziektestadium bij cystectomie, optreden van lymfekliermetastasen of slechtere overleving.

Ten slotte, uit een zeer recent gepubliceerde studie van Hermans et al. [5], waarin gekeken is naar de toepassing van neoadjuvante chemotherapie (NAC) bij patiënten met cystectomie in Nederland, kan geconcludeerd worden dat NAC in de loop van de jaren steeds vaker wordt toegepast (conform de aanbeveling in de richtlijn). Ook deze studie beschrijft een aanzienlijke variatie tussen de ziekenhuizen. Met name jonge patiënten, patiënten met uitgebreide ziekte en patiënten die zijn gediagnosticeerd in academische centra ondergaan vaker NAC. Neoadjuvante radiotherapie en

blaaskanker, een cystectomie ondergaat, versus $65 \%$ van patiënten van 75-79 jaar, ruim $80 \%$ van de patiënten van 
adjuvante behandelingen worden niet of nauwelijks toegepast in Nederland.

Naast openbaarmaking van landelijke cijfers in rapportages en wetenschappelijke publicaties, koppelt IKNL cijfers terug over de zorg voor urologische tumoren op regionaal niveau. Hiertoe is het IKNL vorig jaar gestart met regiorapportages over blaas- en nierkanker. In deze rapportages worden cijfers van een vooraf gespecificeerde groep ziekenhuizen op ziekenhuisniveau weergegeven en vergeleken met een regionaal en een landelijk gemiddelde. De rapportage wordt besproken in een regionale multidisciplinaire bijeenkomst met als doel om samen met de medisch specialisten de variatie in en uitkomsten van de zorg onderling te vergelijken, te discussiëren over mogelijke oorzaken van verschillen en zo te leren van elkaar en daarmee de kwaliteit van de zorg te optimaliseren.

Een voorbeeld van een bevinding die in alle regio's wordt waargenomen en die veel discussie oproept, is de behandeling van patiënten met T1a-niertumoren. Waarbij in sommige ziekenhuizen vrijwel iedere patiënt een nefronsparende behandeling (partiële nefrectomie, radiofrequente $a b-$ latie (RFA) of cryotherapie) ondergaat, zoals door de richtlijn wordt aanbevolen, ondergaat in andere ziekenhuizen een relatief hoog percentage van de patiënten een radicale nefrectomie. Figuur 1 toont, ter illustratie, de variatie in behandeling van deze patiënten tussen een aantal willekeurige ziekenhuizen.

De voorbeelden laten zien dat, op basis van de huidige dataset van de NKR, diverse aspecten van de kwaliteit van urologische kankerzorg in kaart gebracht kunnen worden. Echter, er zijn ook beperkingen. In veel studies wordt variatie in zorg gezien (zoals in de genoemde voorbeelden). Een deel van de geobserveerde variatie zal verklaard kunnen worden door diversiteit in patiënt- en/of tumorkenmerken en/of patiëntvoorkeuren. Het is echter waarschijnlijk, zeker wanneer sprake is van redelijk tot grote variatie, dat deze aspecten niet alle variatie verklaren en dat ook andere factoren een rol spelen, wat betekent dat er mogelijk ruimte is voor verbetering.

Om erachter te komen welke factoren ten grondslag liggen aan de geobserveerde variatie en of deze variatie samenhangt met bepaalde ziekte-uitkomsten, is het van belang om uitgebreide informatie vast te leggen over patiëntkarakteristieken, diagnostische procedures en behandelmodaliteiten, evenals de effecten daarvan op het optreden van recidieven, ziekteprogressie en overleving, maar ook complicaties en toxiciteit. Ook het effect op kwaliteit van leven is hierbij van belang.

Voor colorectaalkanker en hematologische maligniteiten worden, in de vorm van ziektespecifieke registers, binnen de NKR sinds enkele jaren meer en gedetailleerdere data vastgelegd waarmee deze vragen beantwoord kunnen worden. Sinds 2015 wordt dit ook gedaan voor prostaatkanker, dankzij een projectsubsidie die is verkregen via KWF Kankerbestrijding voor het zogeheten ProZIB-register: 'Prostaatkankerzorg In Beeld'.

Najaar 2016 start een vergelijkbare registratie voor blaaskanker (voorlopige werktitel: 'Blaaskankerzorg In Beeld'), eveneens op basis van een subsidie van KWF Kankerbestrijding.

\section{Prostaatkankerzorg In Beeld (ProZIB)}

In nauwe samenwerking met de Nederlandse Vereniging voor Urologie (NVU), de Nederlandse Vereniging voor Radiotherapie en Oncologie (NVRO), de Nederlandse Vereniging voor Pathologie (NVvP) en de Nederlandse Vereniging voor Radiologie (NVvR) is ProZIB gestart.

De hoofddoelstellingen van ProZIB zijn het in kaart brengen van variatie in prostaatkankerzorg, factoren identificeren die met die variatie samenhangen, en inzicht verkrijgen in knelpunten/verbetermogelijkheden, wat uiteindelijk zal leiden tot optimale prostaatkankerzorg. Omdat ProZIB een prospectief verlopende registratie is, waarin nieuwe patiënten die zijn gediagnosticeerd met prostaatkanker worden geïncludeerd, zal de focus in eerste instantie liggen op gelokaliseerde en gemetastaseerde prostaatkanker en niet op castratieresistente prostaatkanker.

Om de doelstellingen van ProZIB te realiseren, wordt van alle nieuwe prostaatkankerpatiënten die zijn gediagnosticeerd tussen 1 oktober 2015 en 15 april 2016, een zeer gedetailleerde dataset vastgelegd. Deze klinische dataset wordt aangevuld met gegevens over kwaliteit van leven van een deel van de patiënten. Op dit moment worden data over de uitgevoerde diagnostische procedures, behandeling en kortetermijn-complicaties/toxiciteit van bijna 6000 prostaatkankerpatiënten geregistreerd (zie www.nvu.nl voor een compleet overzicht). Twee jaar na de diagnose worden aanvullende data verzameld over het verloop van de ziekte (bijvoorbeeld met betrekking tot PSA-progressie en langetermijncomplicaties/toxiciteit). Inmiddels zijn ruim 2800 prostaatkankerpatiënten benaderd met het verzoek een kwaliteit-van-levenvragenlijst in te vullen. Stand van zaken medio 2016: ruim 1900 mensen hebben de vragenlijst ingevuld (respons $67 \%$ ). Ook deze kwaliteit-van-levenmeting wordt één jaar en twee jaar na de diagnose herhaald.

Binnen ProZIB creëren we een dataset waarmee resultaten uit klinische trials in de dagelijkse klinische praktijk geëvalueerd kunnen worden en relevante vraagstukken omtrent de kwaliteit van prostaatkankerzorg in Nederland beantwoord kunnen worden. Ook voor vraagstellingen waarvoor geen trials op grote schaal mogelijk zijn, zoals in de heterogene oudere patiëntpopulatie, zullen deze data van waarde zijn, als het gaat om het bepalen van de effectiviteit van diagnostiek en behandeling van (oudere) patiënten met prostaatkanker. Waarbij natuurlijk wel in ogenschouw 
genomen moet worden dat observationele onderzoeksgegevens op een andere manier geïnterpreteerd moeten worden dan cijfers die verkregen zijn met gerandomiseerde klinische trials.

Tevens kan door de betrokken medisch professionals een set evidencebased 'kwaliteitsindicatoren' geformuleerd worden, die valide en relevant zijn voor het monitoren van prostaatkankerzorg in Nederland (ook door de tijd heen). De informatie die noodzakelijk is voor het meten van die kwaliteitsindicatoren kan onderdeel zijn van de kankerspecifieke gegevensset voor prostaatkanker in de NKR, zodat ProZIB resulteert in een continue multidisciplinaire kwaliteitsmonitor voor prostaatkanker, waarbij door getrainde, onafhankelijke datamanagers van IKNL informatie uit de medische dossiers geëxtraheerd wordt (dus zonder extra registratielast voor de ziekenhuizen).

\section{Pilot cystectomieregistratie door IKNL}

Om de registratielast voor de urologen te verminderen en de onafhankelijkheid van de registratie van cystectomieën te vergroten, is in zeven ziekenhuizen in het zuiden van het land een pilotstudie uitgevoerd waarin IKNL een jaar lang de registratie van cystectomieën in de NVU-database heeft uitgevoerd, in plaats van de urologen. Uit een recente analyse van de cystectomiedata die zijn geregistreerd door de datamanagers van IKNL $(n=131)$ en cystectomiedata die zijn vastgelegd door de urologen zelf (in het jaar daarvoor jaar, $n=166$ ), blijkt dat de verplichte items goed en volledig waren geregistreerd door zowel de urologen als de datamanagers. De niet-verplichte, wat meer gedetailleerde items, zoals datum van laatste positieve TURT, preoperatief $\mathrm{Hb}$, wel/geen bloedtransfusie, werden daarentegen echter vaker ingevuld in de registraties die waren gedaan door de datamanagers. Inhoudelijk bleken de registraties ook vergelijkbaar, met uitzondering van de registratie van complicaties. Datamanagers scoorden vaker graad 1/2-postoperatieve complicaties. Wat betreft graad 3/4-complicaties leken geen verschillen te bestaan.

$\mathrm{Na}$ een positieve evaluatie van de pilot door zowel de urologen uit de deelnemende ziekenhuizen als IKNL, is besloten om voor deze ziekenhuizen de registratie voort te zetten tot aan de start van het Blaaskankerzorg In Beeldproject, waarbij registratie van cystectomieën voor alle ziekenhuizen zal plaatsvinden.

\section{Conclusie}

In dit artikel hebben we u laten zien dat het mogelijk is om met gegevens uit de NKR inzicht te krijgen in de kwaliteit van zorg voor oncologische tumoren. De komende jaren wil IKNL in samenwerking met de NVU en de andere wetenschappelijke verenigingen die betrokken zijn bij de zorg voor patiënten met urologische tumoren verder werken aan het in kaart brengen van de (variatie in) kwaliteit van zorg voor patiënten met een urologische tumor. Om de geobserveerde variatie beter te kunnen verklaren en om mogelijke verbeterpunten te formuleren, is vaak een uitbreiding van de standaardregistratie noodzakelijk. Met behulp van aanvullende financiering is inmiddels voor prostaatkanker een uitgebreidere registratie gestart, blaaskanker volgt. Uitgangspunten bij deze registraties zijn een hoge kwaliteit en uniformiteit van gegevens, onafhankelijkheid en een zo laag mogelijke registratielast van betrokken medisch specialisten.

Open Access This article is distributed under the terms of the Creative Commons Attribution 4.0 International License (http:// creativecommons.org/licenses/by/4.0/), which permits unrestricted use, distribution, and reproduction in any medium, provided you give appropriate credit to the original author(s) and the source, provide a link to the Creative Commons license, and indicate if changes were made.

\section{Literatuur}

1. Goossens-Laan CA, Visser O, Wouters MW, et al. Variations in treatment policies and outcome for bladder cancer in the Netherlands. Eur J Surg Oncol. 2010;36:S100-S107.

2. Visser O, Horenblas S. Kankerzorg In Beeld. Utrecht: IKNL; 2014, pag. 83-6.

3. Bruins HM, Fransen van de Putte E, Verhoeven R, et al. The impact of a minimum cystectomy volume policy on the centralization and quality of bladder cancer care in the Netherlands. Eur Urol. 2014;15:3.

4. Bruins HM, Aben KK, Arends TJ, et al. The effect of the time interval between diagnosis of muscle-invasive bladder cancer and radical cystectomy on staging and survival: A Netherlands Cancer Registry analysis. Urol Oncol. 2016;34166:e1-6.

5. Hermans TJ, Fransen van de Putte E, Horenblas S, et al. Perioperative treatment and radical cystectomy for bladder cancer - a population based trend analysis of 10,338 patients in the Netherlands. Eur J Cancer. 2016;54:18-26.

dr. Katja K.H. Aben senior onderzoeker

dr. Rob Verhoeven senior onderzoeker

mr. Antoinette de Vries senior adviseur 